\title{
A comparison of urine dipstick test with spot urine protein-creatinine ratio and 24 -hour urine protein excretion in women with preeclampsia
}

\author{
Pallavee P*, Nischintha S
}

Department of Obstetrics \& Gynecology, Mahatma Gandhi Medical College \& Research Institute, Puducherry, India

Received: 27 February 2015

Accepted: 19 April 2015

\author{
*Correspondence: \\ Dr. Pallavee P, \\ E-mail: ppallavee@ rediffmail.com
}

Copyright: (c) the author(s), publisher and licensee Medip Academy. This is an open-access article distributed under the terms of the Creative Commons Attribution Non-Commercial License, which permits unrestricted non-commercial use, distribution, and reproduction in any medium, provided the original work is properly cited.

\begin{abstract}
Background: Measurement of protein excretion in a 24-hour urine collection and measurement of protein-creatinine $(\mathrm{P} / \mathrm{C})$ ratio in a spot urine sample have been standard investigations for evaluation of protein excretion. The urine dipstick method, a semi-quantitative method of proteinuria excretion, has long been used as a screening tool for the same purpose. The objective of this study was to assess the efficacy of test dipstick measurement of proteinuria in comparison with 24 hour urinary protein excretion and spot urine protein/creatinine ratio, as a screening test in pregnant patients with suspected preeclampsia, attending an obstetric outpatient service.

Methods: We measured proteinuria in 75 patients attending the obstetric outpatient service at our University Hospital by test dipstick method, 24-hour urine protein excretion and spot urine protein/creatinine ratio and calculated the degree of correlation between the first with the other two standard tests.

Results: The correlation of the urine dipstick test values with the 24-hour urine protein excretion was strong ( $\mathrm{r}=$ $0.634)$, while compared to the spot urine protein/creatinine ratio, it was moderate at best $(\mathrm{r}=0.401)$. The $1+$ level of urine dipstick demonstrated greater sensitivity, but at the $2+$ level, dipstick was more specific in identification of significant proteinuria.

Conclusions: We conclude that test dipstick correlates better with 24 hour urine protein estimation than with the protein/creatinine ratio. Further, $1+$ urine dipstick could be a good screening tool for identifying proteinuria in patients attending the obstetrics outpatient service. However, the $2+$ level on the urine dipstick would be required to serve as be an alternative to the 24-hour urine collection for detection of significant proteinuria or calculation of spot urine $\mathrm{P} / \mathrm{C}$ ratio.
\end{abstract}

Keywords: Dipstick, 24 hour urine protein, Protein/Creatinine ratio, Preeclampsia, Proteinuria

\section{INTRODUCTION}

Proteinuria occurs in preeclampsia as a consequence of reduction in the integrity of glomerular barrier or reduced tubular reabsorption. It remains an important objective criterion for diagnosis of preeclampsia and has been used to classify the severity as well as to predict adverse fetomaternal outcome in preeclampsia. ${ }^{1}$ Among the various methods available to quantify proteinuria, 24-hr urinary protein estimation remains the gold standard. Alternative methods like a spot urine sample Protein-Creatinine (P/C) ratio avoid the influence of variations in urinary solute concentrations and can reduce the delay in diagnosis and management of preeclamptic patients. This approach is based on the fact that in presence of a stable glomerular filtration rate, urinary creatinine excretion has been reported to be fairly constant in a given individual. ${ }^{2}$ However, routine examination of random spot urine samples is usually performed by semi-quantitative tests like urinary dipsticks. 
Though easy to perform, the urinary dipsticks indicate the approximate protein concentration at the time of sampling and fail to give an idea about the total daily excretion of protein. Thus, if the urine output in one day is much less or more than 1 litre, misinterpretation of result is likely to occur.

There are few studies which have examined urine samples from the outpatient department and evaluated the comparability of the $\mathrm{P} / \mathrm{C}$ ratio and 24-h urine protein excretion with the test dipstick method. One such study showed that the correlation between the protein/creatinine ratio and the corresponding dipstick value for albumin was statistically highly significant for all levels of proteinuria. $^{3}$

However, it must be remembered that a positive dipstick protein may be elevated due to other sources of protein, such as blood, semen or vaginal secretions in urine. Further, since it measures primarily albumin, the dipstick may occasionally be normal when significant quantities of other proteins are present in the urine. The aim of the present study was to compare the accuracy of test dipstick with spot urinary protein/creatinine ratio $(\mathrm{P} / \mathrm{C})$ and with the 24-hour urine protein excretion.

\section{METHODS}

The protocol for the study was fixed up in advance and strict adherence ensured. The observational correlation clinical study was conducted after obtaining clearance from the hospital ethics committee. This was a prospective study conducted over 18 months, among pregnant women reporting to the hospital with a suspicion of preeclampsia. Participants were recruited from the outpatient department of the hospital. They gave informed consent before taking part in the study.

\section{Participants}

Primigravida with singleton pregnancy, having cephalic presentation, and diagnosed as preeclampsia were included in the study. Preeclampsia was diagnosed based on blood pressure recordings of $140 / 90 \mathrm{mmHg}$ or greater on at least two occasions, a minimum of 4 hours apart, or with single diastolic blood pressure reading $\geq 110 \mathrm{mmHg}$ after the $20^{\text {th }}$ week of pregnancy, along with proteinuria $\geq 1+$ detected by dipstick urine analysis.

Women with prior history of renal disease, chronic hypertension, urinary tract infection, pathological vaginal discharge and those who delivered prior to completion of collection of a 24-h urine sample were excluded from the study. Also excluded were women who had performed heavy exercise $(>1$ hour of vigorous exercise on the day of urine collection), bed rest longer than 24 hours and gestational diabetes mellitus. 75 pregnant women were recruited. All the patients were briefed in detail regarding urine tests to be performed upon them over the next 24 hours.

\section{Trial procedures}

Participants were instructed to collect a midstream urine sample for estimation of the spot urine $\mathrm{P} / \mathrm{C}$ ratio and qualitative urinary protein estimation by dipstick, graded as $1+$ or $2+$. They were then asked to collect the $24-\mathrm{h}$ urine starting with the second urine sample of the morning (after discarding the first sample of the day) till the first sample collected the following morning.

The urine $\mathrm{P} / \mathrm{C}$ ratio was calculated by dividing the urinary protein concentration by the urinary creatinine concentration. Urine protein was estimated by the urinary-cerebrospinal fluid protein method, an adaptation of the pyrogallol red-molybdate method.

Urine creatinine was estimated by the CREA method, a modification of the Jaffe's reaction. Both tests were performed using an automated analyzer. All patients were followed up till delivery. The protein/creatinine ratio, dipstick and 24-hour protein excretion were then compared. Reference ranges for protein/creatinine ratio was taken as $<0.3$ and $\geq 0.3$. 24-h urine protein excretion was graded into 3 groups: $<300 \mathrm{mg}, 300-1000 \mathrm{mg}$ and $>1000 \mathrm{mg}$. Dipstick was graded $1+$ and $2+$.

\section{Statistical analysis}

We determined that a recruitment target of 75 provided an allowable error of $10 \%$ based upon prevalence rate of $25 \%$. The strengths of the correlation between the automated dipstick urinalysis and 24-h proteinuria and the urine protein-creatinine ratio were determined by Pearson's correlation.

The sensitivity and specificity were calculated using each observed level of the urinalysis and the urine proteincreatinine ratio and the 24 -h collection thresholds for a positive test.

The Likelihood Ratios (LRs) for dipstick testing were calculated at two levels, using ranges of the urine protein-creatinine ratio and $24-\mathrm{h}$ urine protein excretion.

\section{RESULTS}

75 pregnant women diagnosed as having preeclampsia were recruited for the study. The age and region-wise distribution of the patients are shown in (Table $1 \& 2$ respectively).

Table 3 shows the distribution of the periods of gestation of these patients. $73.3 \%$ patients had mild preeclampsia (proteinuria of $1+$ using urine dipstick analysis), while, $26.7 \%$ had severe preeclampsia (proteinuria of $\geq 2+$ with urine dipstick). Table 4 demonstrates the distribution of patients as per their urine dipstick analysis, 24-h urine protein and spot urine $\mathrm{P} / \mathrm{C}$ ratio. 
Pearson's correlation test depicted a strong positive correlation between 24-h urine protein and test dipstick ( $r$ $=0.634$ ) with $\mathrm{a} \mathrm{P}=0.01$ which was strongly significant (Table 5). However, correlation by Pearson's test between spot $\mathrm{P} / \mathrm{C}$ ratio and test Dip stick was moderate with $\mathrm{r}=0.401$, with a $\mathrm{P}=0.01$ (Table 6).

Table 1: Age distribution of patients studied.

\begin{tabular}{|llll|}
\hline Age (years) & 1+ Dipstick & 2+ Dipstick & Total \\
\hline$\leq 20$ & $2(3.6 \%)$ & $5(25 \%)$ & $7(9.3 \%)$ \\
\hline $21-25$ & $26(47.3 \%)$ & $5(25 \%)$ & $31(41.3 \%)$ \\
\hline $26-30$ & $24(43.6 \%)$ & $9(45 \%)$ & $33(44 \%)$ \\
\hline $31-35$ & $3(5.5 \%)$ & $0(0 \%)$ & $3(4 \%)$ \\
\hline$>35$ & $0(0 \%)$ & $1(5 \%)$ & $1(1.3 \%)$ \\
\hline Total & $55(100 \%)$ & $20(100 \%)$ & $75(100 \%)$ \\
\hline Mean \pm SD & $25.55 \pm 3.11$ & $24.80 \pm 4.64$ & $25.35 \pm 3.56$ \\
\hline
\end{tabular}

Samples are age matched with $\mathrm{P}=0.427$
Table 2: Region-wise distribution.

\begin{tabular}{|llll|}
\hline Address & 1+ Dipstick & 2+ Dipstick & Total \\
\hline Rural & $39(70.9 \%)$ & $14(70 \%)$ & $53(70.7 \%)$ \\
\hline Urban & $16(29.1 \%)$ & $6(30 \%)$ & $22(29.3 \%)$ \\
\hline Total & $55(100 \%)$ & $20(100 \%)$ & $75(100 \%)$ \\
\hline
\end{tabular}

$\mathrm{P}=0.939$

Table 3: Period of gestation (weeks).

\begin{tabular}{|llll|}
\hline $\begin{array}{l}\text { POG } \\
(\text { weeks })\end{array}$ & 1+ Dipstick & 2+ Dipstick & Total \\
\hline $28-32$ & $1(1.8 \%)$ & $3(15 \%)$ & $4(5.3 \%)$ \\
\hline $33-36$ & $12(21.8 \%)$ & $8(40 \%)$ & $20(26.7 \%)$ \\
\hline $37-40$ & $42(76.4 \%)$ & $9(45 \%)$ & $51(68 \%)$ \\
\hline Total & $55(100 \%)$ & $20(100 \%)$ & $75(100 \%)$ \\
\hline Mean \pm SD & $37.44 \pm 2.03$ & $35.50 \pm 2.46$ & $36.20 \pm 2.31$ \\
\hline
\end{tabular}

Table 4: Period of gestation (weeks).

\begin{tabular}{|c|c|c|c|c|c|c|}
\hline \multicolumn{2}{|c|}{ Test Dipstick } & \multicolumn{3}{|c|}{ 24-h urine protein excretion (mg) } & \multicolumn{2}{|c|}{ Spot urine $\mathrm{P} / \mathrm{C}$ ratio } \\
\hline $1+$ & $2+$ & $<300$ & $300-1000$ & $>1000$ & $<0.3$ & $>0.3$ \\
\hline $55(73.3 \%)$ & $20(26.7 \%)$ & $41(54.7 \%)$ & $34(45.3 \%)$ & - & $9(12.3 \%)$ & $66(87.7 \%)$ \\
\hline Total $=75$ & & Total $=75$ & & & Total $=75$ & \\
\hline
\end{tabular}

P / C: Protein / Creatinine

Table 5: Correlation of Dip stick with 24-h urine protein excretion.

\begin{tabular}{|c|c|c|c|c|}
\hline \multirow{2}{*}{$\begin{array}{l}\text { Dip } \\
\text { stick }\end{array}$} & \multicolumn{2}{|c|}{$\begin{array}{l}\text { 24-h urine protein } \\
\text { excretion }\end{array}$} & \multirow{2}{*}{$\begin{array}{l}\text { Pearson } \\
\text { correlation } \\
\text { (r) }\end{array}$} & \multirow[b]{2}{*}{$P$ value } \\
\hline & $\begin{array}{l}<300 \\
(n=41)\end{array}$ & $\begin{array}{l}300-1000 \\
(n=34)\end{array}$ & & \\
\hline+1 & $40(97.6 \%)$ & $15(44.1 \%)$ & \multirow{2}{*}{0.634} & \multirow{2}{*}{$<0.01 * *$} \\
\hline+2 & $1(2.4 \%)$ & $19(55.9 \%)$ & & \\
\hline
\end{tabular}

Table 6: Correlation of Dip stick with spot $\mathrm{P} / \mathrm{C}$ ratio.

\begin{tabular}{|c|c|c|c|c|}
\hline \multirow[b]{2}{*}{$\begin{array}{l}\text { Dip } \\
\text { stick }\end{array}$} & \multicolumn{2}{|c|}{ Spot $\mathrm{P} / \mathrm{C}$ ratio } & \multirow{2}{*}{$\begin{array}{l}\text { Pearson } \\
\text { correlation } \\
\text { (r) }\end{array}$} & \multirow[b]{2}{*}{$P$ value } \\
\hline & $\begin{array}{l}<0.30 \\
(n=9)\end{array}$ & $\begin{array}{l}\geq 0.30 \\
(n=66)\end{array}$ & & \\
\hline+1 & $9(100.0 \%)$ & $46(69.7 \%)$ & \multirow{2}{*}{0.401} & \multirow{2}{*}{$<0.01 * *$} \\
\hline+2 & 0 & $20(30.3 \%)$ & & \\
\hline
\end{tabular}

P/C: Protein/Creatinine

Figure 1 shows the results of dipstick testing in relation to the total urinary protein excretion over 24 hours. 24-h urinary protein excretion was less than $300 \mathrm{mg}$ in 40 of the 41 patients with $1+$ proteinuria on dipstick testing. The sensitivity and specificity were calculated for each of the two levels of test dipstick $1+$ and $2+$ in comparison to 24-h urine protein excretion. Sensitivity of $1+$ proteinuria was found to be $97.56 \%$ (CI $87.1 \%$ to $99.59 \%$ ), while specificity was $55.88 \%$ (CI $37.89 \%$ to $72.8 \%)$. Similarly, sensitivity of $2+$ proteinuria was found to be $55.88 \%$ (CI $37.89 \%$ to $72.8 \%$ ), while specificity was $97.56 \%$ (CI $87.1 \%$ to $99.59 \%$ ). Similarly, we also calculated the likelihood ratios (LRs) for both levels of proteinuria in comparison to the 24-h urine protein excretion. In general, a diagnostic test with an LR of $>10$ or $<0.10$ changes pretest probability dramatically and is considered a strong diagnostic test. The positive LR of urine $1+$ dipstick was found to be 2.21 (CI 1.51 to 3.24), while the negative LR was 0.04 (CI 0.01 to 0.31). Similarly, for $2+$ dipstick, the positive LR was found to be 22.91 (CI 3.23 to 162.47), while the negative LR was 0.45 (CI 0.31 to 0.66 ).

Figure 2 shows the results of dipstick testing in relation to the urinary $\mathrm{P} / \mathrm{C}$ ratio. All of the patients, who had a urinary $\mathrm{P} / \mathrm{C}$ ratio of less than 0.3 , demonstrated $1+$ proteinuria. The sensitivity and specificity were defined for the two levels of urinary dipstick in relation to the urinary $\mathrm{P} / \mathrm{C}$ ratio. Sensitivity of $1+$ proteinuria on test dipstick was detected to be $100 \%$ (CI $66.21 \%$ to $100 \%$ ), while specificity was only $30.3 \%$ (CI $19.6 \%$ to $42.85 \%$ ). Similarly for the $2+$ urine dipstick, the sensitivity was 
$30.3 \%$ (CI $19.6 \%$ to $42.85 \%$ ), while the specificity was $100 \%$. The positive LR of urine $1+$ dipstick was found to be 1.43 (CI 1.22 to 1.68 ), while the negative LR was 0 . Similarly, for $2+$ dipstick, the positive LR could not be calculated, while the negative LR was 0.7 (CI 0.59 to 0.82).

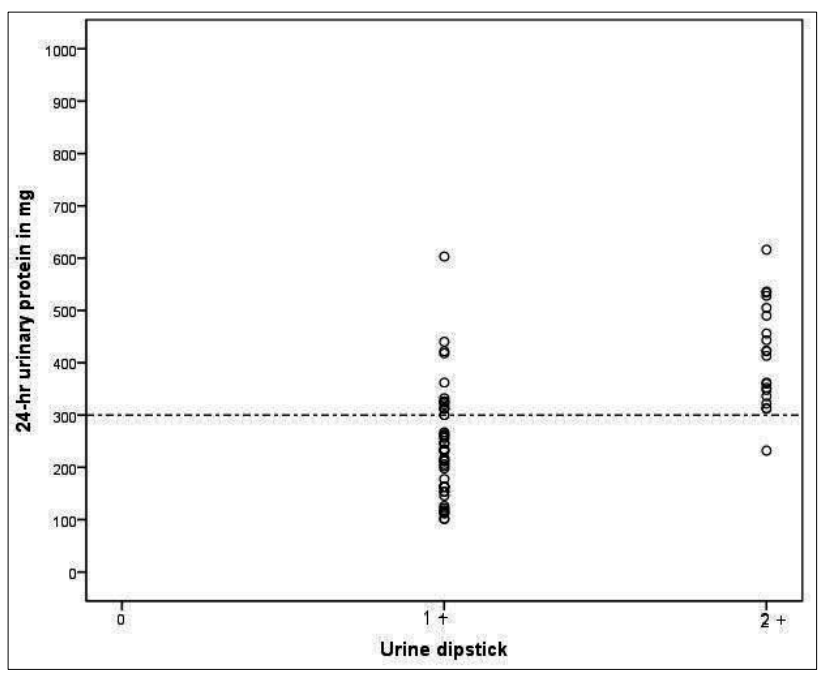

Figure 1: Comparison of dipstick testing and 24 hour quantitative protein excretion in 75 patient samples.

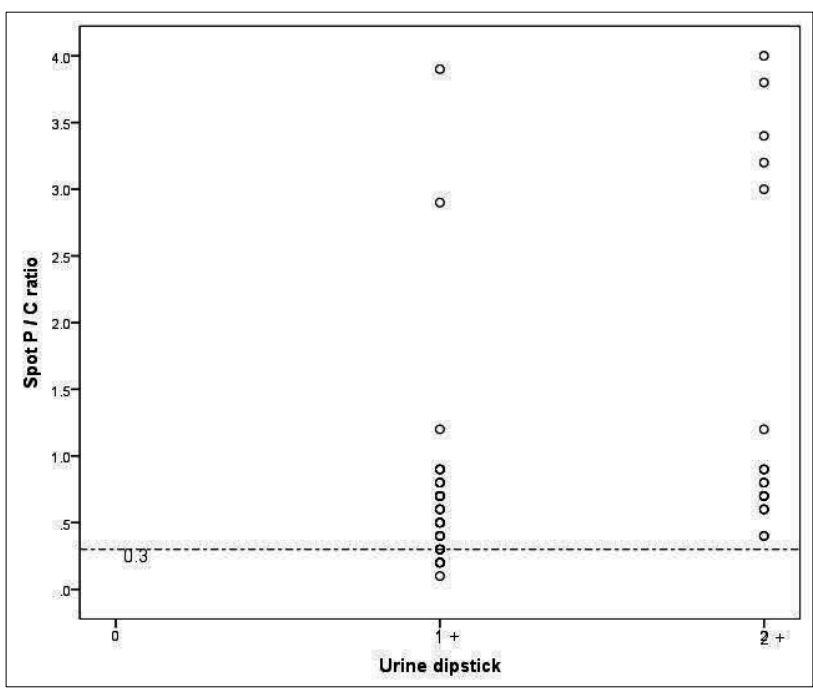

Figure 2: Comparison of dipstick testing and spot urine $\mathrm{P} / \mathrm{C}$ ratio excretion in 75 patient samples.

\section{DISCUSSION}

A correlation of the test dipstick method with standard urinary tests for preeclampsia such as the spot urine P/C ratio and the 24-h urine protein excretion showed that the dipstick method correlated more strongly $(r=0.634)$ with the 24-h urine protein excretion method as compared to a moderate correlation $(\mathrm{r}=0.401)$ with the $\mathrm{P} / \mathrm{C}$ ratio. Because of its high sensitivity, the $1+$ urine dipstick level appears to be useful as a screening test for spot urine samples for the presence of protein if the patient is having preeclampsia. At the $2+$ level, urine dipstick appears to be more specific for detection of proteinuria, but could grossly underperform if this level were to be used as a screening test. Further, our study was conducted in patients without any pre-existing renal disorder, and in patients who have such disorders a quantitative test would definitely be indicated.

Our results show that the convenience of using only qualitative tests for urinary protein detection such as test dipsticks may sacrifice the accuracy of diagnosis of proteinuria and potentially compromise the safety of the patient and her pregnancy. While these tests may be used in the routine screening of normal pregnant women, quantitative tests may be better options in subjects in whom early and definitive diagnosis of proteinuria is important, e.g. in suspected cases of hypertensive pregnancies, preeclampsia, and HELLP (Hemolysis, Elevated Liver enzymes, and Low Platelet count) syndrome.

24 hour urine collection, which is the gold standard used to estimate proteinuria is cumbersome, and aesthetically unacceptable. Hence a spot urine examination would be more acceptable and less time consuming. The usefulness of spot urine sampling using the protein/creatinine ratio and test dipstick was thus tested against the commonly used 24-hour urine protein excretion.

The $\mathrm{P} / \mathrm{C}$ ratio takes into account the fact that creatinine excretion remains fairly constant in the presence of a stable GFR. The protein excretion would also likewise be fairly stable. Hence the ratio of the two in a single voided sample would reflect the cumulative protein excretion over the day, as the two stable rates would cancel out the time factor. ${ }^{4}$

In a study on 26 children below 12 years of age, having nephrotic syndrome, the correlation between the $\mathrm{P} / \mathrm{C}$ ratio and the corresponding dipstick value for albumin was statistically highly significant $(\mathrm{P} \leq 0.001)$ for all levels of proteinuria. ${ }^{3}$ In this study, the sample soon after the first voided sample was taken. In contrast, our sample collection strategy included one random mid-stream urine sample collected in the OPD for estimating the spot urine $\mathrm{P} / \mathrm{C}$ ratio and doing the test dipstick. Further sample collection for the 24-h urine started from the second urine sample till the first urine sample the next day morning.

The $\mathrm{P} / \mathrm{C}$ ratio is a method of rapid quantitative assessment of proteinuria. All patients had normal creatinine clearance as estimated by serum creatinine and height index. However the random dipstick test was reliable only when significant proteinuria was present. It did not correlate well when the proteinuria was in the lower range. Correlation with creatinine clearance was not looked at. In the presence of stable renal function a $\mathrm{P} / \mathrm{C}$ ratio of less than 0.3 can be taken to be within normal limits. 
Previous reports on test dipstick have suggested that, neither the presence nor severity of proteinuria can be confidently predicted by such method alone..$^{5-7}$

In our study, where dipstick readings were of the order of $1+$, there was a high incidence of false positives when compared to both 24-h urine protein $(27 \%)$, as also the urinary $\mathrm{P} / \mathrm{C}$ ratio, though it should be emphasised that dipstick readings of $2+$ correctly predicted the presence of significant proteinuria in most cases. The urine dipstick test currently used is semi-quantitative. Also as stated above, compared with the quantitative methods the dipstick has sensitivity limitations. The urinary protein results can also be affected by variations in sample concentrations. Thus, physicians cannot distinguish between pathological proteinuria and false positives caused by concentrated samples when the urinary protein report shows less than $1+$ or "trace". The $\mathrm{P} / \mathrm{C}$ ratio can act as an indicator to detect over-diluted samples which have less than $10 \mathrm{mg} / \mathrm{dL}$ of urinary creatinine. When negative protein results are found in over-diluted samples, the samples should be re-collected and reexamined to ensure accurate results. About $10 \%$ of routine urine screening samples are estimated to be diluted samples. That also means without the $\mathrm{P} / \mathrm{C}$ ratio, the diagnosis of proteinuria will be underestimated because of false negative results.

Since conventional dipsticks have sensitivity and specificity limitations, the urinary protein results could be false positive or false negative. If the false results are not detected, the consequences can be serious due to delays in diagnosis and treatment. However, it is costly to retest false negative data.

Our data seems to suggest that urinalysis with the test dipstick is reasonably specific at the $2+$ level, but at its most sensitive diagnostic level $(1+)$ will over-diagnose preeclampsia.

On the basis of our study results, we recommend that in patients with suspected preeclampsia, an initial screen, an automated dipstick urinalysis should be performed. If the urinalysis has $2+$ protein or greater, the patient most likely has significant proteinuria. If the urinalysis is negative for protein or is $1+$, urine $\mathrm{P} / \mathrm{C}$ ratio should be ordered to further define risk. If the urine $\mathrm{P} / \mathrm{C}$ ratio is $\geq 0.3$, the patient most likely has significant proteinuria. If the urine protein-creatinine ratio is $<0.3$, further evaluation with a 24-h urine collection may be warranted.

This systematic approach would be better at providing more accurate and earlier as well as cost-effective diagnostic information than the traditional automated dipstick urinalysis alone. With the traditional urinalysis by test dipstick, using $\geq 1+$ as a cutoff, the presence of significant proteinuria may be over-diagnosed. Owing to the greater numbers of false positives with $1+$ proteinuria, compared to both 24-h urine protein excretion and the $\mathrm{P} / \mathrm{C}$ ratio, test dipstick may not be effective in deciding definitely, which patients need to be managed as preeclamptics. Using the test dipstick combined with the urine $\mathrm{P} / \mathrm{C}$ ratio and the 24-h urine protein excretion in a strategy as outlined here, absence or presence of significant proteinuria may be more timely and cost-effectively made.

In many cases, precise assessment of the degree of proteinuria is unnecessary. Rather, the clinician is more interested in classifying patients into broad categories by the degree of proteinuria, in order to decide which patients require further investigation. In this study we found that the correlation between the test dipstick was stronger with the 24-h urinary protein excretion than with spot urinary $\mathrm{P} / \mathrm{C}$ ratio. However to be of practical value, the $1+$ level of test dipstick may require further elucidation with quantitative testing, whereas, at the $2+$ level on the dipstick, most patients would be having significant proteinuria, which may or may not be further investigated at the discretion of the clinician. A wider application of this technique seems indicated in view of its advantages in terms of time, increased patient convenience, and reduced costs.

\section{CONCLUSION}

Based on the findings of the present study, we conclude that a urine test dipstick correlates strongly with 24-hour urine protein excretion and moderately with the urine $\mathrm{P} / \mathrm{C}$ ratio with high accuracy. This test at the $2+$ level, could therefore be an alternative to the 24-hour urine collection for detection of significant proteinuria or calculation of spot urine $\mathrm{P} / \mathrm{C}$ ratio for screening pregnant women with suspected preeclampsia, attending the obstetric outpatient department. However, patients with $1+$ proteinuria, need to undergo further quantitative testing for reliably stratifying their degree of proteinuria.

\section{Funding: No funding sources \\ Conflict of interest: None declared}

Ethical approval: The study was approved by the hospital ethics committee

\section{REFERENCES}

1. Cunningham FG, Leveno KJ, Bloom SL, Hauth JC, Rouse DJ, Spong CY. Pregnancy hypertension In: Twickler DM, Wendel GD, eds. Williams's Obstetrics. 23rd ed. New York: McGraw Hill; 2010: 709-713.

2. Vestergaard P, Leverett R. Constancy of urinary creatinine excretion. J Lab Clin Med. 1958;51:211-8.

3. Agarwal I, Kirubakaran C, Markandeyulu, Selvakumar. Quantitation of proteinuria by spot urine sampling. Indian J Clin Biochem. 2004;19:457.

4. Ginsberg JM, Chang BS, Matarese RA, Garella S. Use of single voided urine samples to estimate quantitative proteinuria. $\mathrm{N}$ Engl $\mathrm{J}$ Med. 1983;309(25):1543-6. 
5. Barratt TM, McLainc PN, Soothill JF. Albumin excretion as a measure of glomerular dysfunction in children. Arch Dis Child. 1971;45:496-501.

6. Gyure WL. Comparison of several methods for semiquantitative determination of urinary protein. Clin Chem. 1977;23(5):876-9.
7. Rennie DB, Keen H. Evaluation of clinical methods in detecting proteinuria. Lancet. 1967;2:489-92.

DOI: $10.18203 / 2320-1770$. ijrog 20150057

Cite this article as: Pallavee $\mathrm{P}$, Nischintha $\mathrm{S}$. A comparison of urine dipstick test with spot urine protein-creatinine ratio and 24-hour urine protein excretion in women with preeclampsia. Int J Reprod Contracept Obstet Gynecol 2015;4:589-94. 